\title{
Long-term survival of thoracoscopic surgery compared with open surgery for clinical NO adenocarcinoma
}

\author{
Shin-ichi Yamashita ${ }^{1,2}$, Keita Tokuishi ${ }^{1}$, Toshihiko Moroga ${ }^{1}$, Asahi Nagata ${ }^{2}$, Naoko Imamura ${ }^{1}$, \\ So Miyahara ${ }^{1}$, Yasuhiro Yoshida ${ }^{2}$, Ryuichi Waseda ${ }^{1}$, Toshihiko Sato ${ }^{1}$, Takeshi Shiraishi ${ }^{1}$, Kazuki Nabeshima ${ }^{3}$, \\ Katsunobu Kawahara ${ }^{4}$, Akinori Iwasaki ${ }^{1}$
}

${ }^{1}$ Department of General Thoracic, Breast, and Pediatric Surgery, Faculty of Medicine, Fukuoka University, Fukuoka, Japan; ${ }^{2}$ General Thoracic and Breast Surgery Center, Fukuoka University Chikushi Hospital, Fukuoka, Japan; ${ }^{3}$ Department of Pathology, Fukuoka University Hospital, Fukuoka, Japan; ${ }^{4}$ Department of Thoracic Surgery, Kitsuki Central Hospital, Kitsuki, Japan

Contributions: (I) Conception and design: S Yamashita; (II) Administrative support: T Sato, T Shiraishi, K Nabeshima, K Kawahara, A Iwasaki; (III) Provision of patients A Nagata, Y Yoshida, N Imamura, R Waseda; (IV) Collection and assembly of data: K Tokuishi, T Moroga, S Miyahara; (V) Data analysis and interpretation: S Yamashita, K Tokuishi; (VI) Manuscript writing: All authors; (VII) Final approval of manuscript: All authors.

Correspondence to: Shin-ichi Yamashita, MD. Department of General Thoracic, Breast, and Pediatric Surgery, Faculty of Medicine, Fukuoka University, 7-45-1 Nanakuma, Jonanku, Fukuoka 814-0180, Japan. Email: yamashi1@fukuoka-u.ac.jp.

Background: Early stage non-small cell lung cancer (NSCLC) is good candidate for video-assisted thoracoscopic surgery (VATS). Long-term outcome compared between VATS and open surgery remains unclear. The aim of this study was to assess the long-term outcome of VATS in early stage adenocarcinoma.

Methods: A retrospective study was performed in 546 patients which were operated between January 2006 and December 2010 in our institute and of those, 240 (220 lobectomies, and 20 segmentectomies) were clinical N0 adenocarcinoma. One hundred and thirty-five patients underwent VATS and 105 patients for open surgery. Long-term oncological outcomes were compared in both groups.

Results: There were significant differences in age, gender, Blinkman index, clinical $T$ factor and tumor size between two groups. VATS group showed statistically longer operation time $(\mathrm{P}=0.01)$, less blood loss $(\mathrm{P}=0.005)$, shorter length of stay $(\mathrm{P}=0.001)$, and less dissected number of lymph nodes $(\mathrm{P}<0.001)$ compared with open surgery. Disease-free survival in VATS was significantly better than open surgery (5- and 10-year survival; VATS, 91.4\%, 79.0\%; open, $85.1 \%, 73.6 \%$; respectively, $\mathrm{P}=0.04)$. Overall survival in VATS was not different from open $(\mathrm{P}=0.58)$. Propensity matched disease-free and overall survival was not significantly different between two groups. Multivariate Cox regression analysis showed that age $[\mathrm{P}=0.04,95 \%$ confidence interval (CI): (1.02-6.81)] in overall and $\mathrm{T}$ factor [P=0.01, 95\% CI: (1.41-17.3)] in disease-free survival was prognostic significant after propensity matching.

Conclusions: Our study demonstrated that long-term outcome in VATS for early stage adenocarcinoma was equivalent to open surgery. VATS may be a treatment of choice for promising long-term prognosis.

Keywords: Lung cancer; video-assisted thoracoscopic surgery (VATS); long-term results

Submitted Jun 20, 2020. Accepted for publication Oct 10, 2020.

doi: $10.21037 /$ jtd-20-2259

View this article at: http://dx.doi.org/10.21037/jtd-20-2259

\section{Introduction}

Video-assisted thoracoscopic surgery (VATS) lobectomy is not a new technique but wide-spread for early-stage non-small cell lung cancer (NSCLC) operation (1). VATS has become more popular and increasing in many centers worldwide. It has been elucidated that VATS was safe and feasible but lacking evidence is adequately powered randomized control study to compare oncological outcomes with open procedures. Many single institutional studies were reported to evaluate that VATS lobectomy 
was equivalent to open lobectomy (2-4), however, VATS lobectomy is not a same operation as an open lobectomy. As previously reported, nodal upstaging under VATS was lower than open procedure from Danish Data Base (5), STS Data Base (6) and National Cancer Data Base (7). VATS lobectomy may lead to undertreatment and worse survival outcomes with clinical stage I NSCLC from these evidences. On the other hand, D'Amico et al. showed that there was no difference between VATS and open lobectomy in terms of number dissected lymph node stations from NCCN Data Base (8). Propensity-score matched analysis shows no difference in survival between patients undergoing VATS and open lobectomy from ACOSOG z0030 trial (9).

VATS is less invasive and provides benefits due to rapid postoperative recovery and shorter length of stay (10). The most of previous reports are retrospective analyses which provide a definitive evidence to compare short-term outcome and median duration of survival (2-4).

The purpose of this study was to evaluate the longterm outcome of VATS lobectomy for clinical N0 NSCLC compare with open lobectomy. We present the following article in accordance with the STROBE reporting checklist (available at http://dx.doi.org/10.21037/jtd-20-2259).

\section{Methods}

\section{Patients}

A retrospective study was performed in 546 patients which were operated between January 2006 and December 2010 in our institute for primary NSCLC. Of those, 240 cases were clinical N0 patients and retrospectively reviewed in this study. Clinical and pathological staging was diagnosed on the $8^{\text {th }}$ edition of the TNM classification of the UICC (11). Histological subtype of adenocarcinoma was classified on the WHO system (12). Postoperative parameters including operative time, blood loss, number of dissected lymph nodes, postoperative complications, duration of chest tube drainage, and length of postoperative hospital stay were compared between the two patient groups. Lymph node metastasis was evaluated histologically by hematoxylin-eosin staining. Patient follow-up was performed every 3 months for the first 2 years, then every 6 months until 5 years, and yearly after 5 years. We defined long-term survival observed from follow up period longer than 5 years. Computed tomography scan was performed every 6 months until 5 years and annually after 5 years. Pathological confirmation of disease recurrence was not mandatory in case of evidence with clinical and radiographic findings of recurrence. The study was conducted in accordance with the Declaration of Helsinki (as revised in 2013). Our institutional ethical committee approved the retrospective study and waived the need for patient consent (No. 12-2-10).

\section{Operative procedure}

Our surgical technique is similar to previous reports (13); essentially, four or five trocars were inserted. In the cases of preoperatively undiagnosed tumor, needle biopsy or wedge resection in order to confirm the intraoperative pathological diagnosis. All procedures were performed by visualization through a television monitor, so-called complete VATS or total thoracoscopy. Thoracotomy (open surgery) was performed by posterolateral thoracotomy with fourth or fifth intercostals incision. Both procedures were followed by systemic mediastinal lymph node dissection. The selection of VATS or open surgery was decided by the patients and surgeon's preference. However, surgeon tend to prefer open surgery for patients with larger tumor than $3 \mathrm{~cm}$ in diameter on the basis of no clinical evidence of nodal metastasis.

\section{Statistical analysis}

All statistical analysis was performed using SPSS 14.0 (SPSS Japan Inc., Tokyo, Japan). The different variables were analyzed with the chi-square test or Fisher's exact test. Continuous nonparametric data was analyzed by MannWhitney U test. Disease-free and overall survival was analyzed using the Kaplan-Meier method and evaluated by the log-rank test. For propensity score analyses, we estimated the probability using logistic regression analysis. This model included variables such as age, gender, Brinkman index (BI), clinical tumor size, clinical $\mathrm{T}$ factor, and clinical $\mathrm{N}$ factor. Cox regression analyses were performed for comparing the disease-free and overall survivals of patients on each procedure while adjusting for propensity score. Statistically significant differences were accepted at $\mathrm{P}<0.05$.

\section{Results}

Patients and tumor characteristics are summarized in Table 1. All cases were 240 patients with clinical N0 adenocarcinoma operated in our institute during study period. There were significant differences between two groups in terms of age, 
Table 1 Characteristics of the patients

\begin{tabular}{|c|c|c|c|}
\hline Characteristics & VATS $(n=135)$ & $\begin{array}{l}\text { Thoracotomy } \\
(n=105)\end{array}$ & $P$ \\
\hline Age & 65 [41-88] & 69 [41-89] & 0.003 \\
\hline Sex, n [\%] & & & 0.04 \\
\hline Male & $55[41]$ & $51[48]$ & \\
\hline Female & 80 [59] & $53[52]$ & \\
\hline $\mathrm{BI}$ & $285.1[0-4,200]$ & $438.3[0-3,200]$ & 0.052 \\
\hline C-T factor & & & $<0.0001$ \\
\hline $\mathrm{T} 1 \mathrm{a}$ & 34 & 7 & \\
\hline $\mathrm{T} 1 \mathrm{~b}$ & 66 & 30 & \\
\hline T1c & 29 & 31 & \\
\hline $\mathrm{T} 2 \mathrm{a}$ & 4 & 22 & \\
\hline $\mathrm{T} 2 \mathrm{~b}$ & 2 & 6 & \\
\hline T3 & 0 & 9 & \\
\hline $\mathrm{T} 4$ & 0 & 1 & \\
\hline $\mathrm{p}-\mathrm{T}$ factor & & & $<0.0001$ \\
\hline Tis/T1mi & $1 / 10$ & $0 / 2$ & \\
\hline $\mathrm{T} 1 \mathrm{a}$ & 23 & 8 & \\
\hline $\mathrm{T} 1 \mathrm{~b}$ & 63 & 29 & \\
\hline $\mathrm{T} 1 \mathrm{c}$ & 29 & 31 & \\
\hline $\mathrm{T} 2 \mathrm{a}$ & 8 & 19 & \\
\hline $\mathrm{T} 2 \mathrm{~b}$ & 1 & 10 & \\
\hline T3 & 0 & 4 & \\
\hline $\mathrm{T} 4$ & 0 & 2 & \\
\hline \multicolumn{4}{|l|}{$\mathrm{c}-\mathrm{N}$ factor } \\
\hline NO & 135 & 105 & \\
\hline $\mathrm{p}-\mathrm{N}$ factor & & & 0.79 \\
\hline No & 133 & 103 & \\
\hline N2 & 2 & 2 & \\
\hline c-tumor size & $1.8(0.6-4.5)$ & $2.9(0.5-8)$ & $<0.001$ \\
\hline p-tumor size & $1.7(0.6-4.5)$ & $2.8(0.4-11)$ & $<0.001$ \\
\hline \multicolumn{2}{|c|}{ Histological subtype } & & 0.21 \\
\hline Mixed & 102 & 88 & \\
\hline Papillary & 17 & 9 & \\
\hline Acinar & 3 & 3 & \\
\hline Lepidic & 2 & 2 & \\
\hline
\end{tabular}

Table 1 (continued)
Table 1 (continued)

\begin{tabular}{|c|c|c|c|}
\hline Characteristics & VATS $(n=135)$ & $\begin{array}{l}\text { Thoracotomy } \\
\quad(n=105)\end{array}$ & $P$ \\
\hline AIS/MIA & $1 / 10$ & $0 / 2$ & \\
\hline Others & 0 & 1 & \\
\hline Operation & & & 0.41 \\
\hline Lobectomy & 122 & 98 & \\
\hline Segmentectomy & 13 & 7 & \\
\hline
\end{tabular}

gender, Brinkman index (BI), clinical $\mathrm{T}$ factor, clinical $\mathrm{N}$ factor and clinical tumor size. These factors led to more advanced pathological $\mathrm{T}$ factor, pathological $\mathrm{N}$ factor, and pathological tumor size in thoracotomy group. All cases with adenocarcinoma were sub-classified according to WHO classification including 190 mixed (Acinar/ papillary), 26 papillary, 6 acinar, 4 lepidic subtype. Thirteen cases of minimally invasive adenocarcinoma (MIA) and/ or adenocarcinoma in situ (AIS) were also classified as independent subtype. Two hundred and twenty lobectomies (VATS 120; thoracotomy 98) including one bi-lobectomy and 20 segmentectomies (VATS 13; thoracotomy 7) were undergone. Only one case in VATS group was converted from VATS to open because of bleeding. Table 2 shows perioperative outcomes between two groups in terms of operation time, blood loss, duration of chest tube drainage, duration of hospital stay, dissected lymph node number, upstaging, morbidity and mortality. VATS group had a longer operation time $(\mathrm{P}=0.01)$, less blood loss $(\mathrm{P}=0.005)$, shorter hospital stay $(\mathrm{P}=0.001)$ and less number of harvested lymph nodes $(\mathrm{P}<0.001)$, however, the other factors were not different. The rates of postoperative morbidity were not statistically significant between VATS (17\%) and open (24\%) surgery. Only one case in thoracotomy group was dead by acute respiratory failure. Two cases in each group were upstaged postoperatively.

After review of baseline characteristics in Table 1, since there were significant differences which may lead to bias confounding factors, we reevaluated characteristics under propensity score matching (Table 3). The differences between two groups underlying all characteristics were eliminated after this analysis. Perioperative outcomes after matched pair analysis showed no difference between 
Table 2 Perioperative outcomes

\begin{tabular}{|c|c|c|c|}
\hline Characteristics & VATS $(n=135)$ & Thoracotomy $(n=105)$ & $P$ \\
\hline Blood loss & $97[5-800]$ & $171[0-2,400]$ & 0.005 \\
\hline Duration of drainage & $4.4[1-14]$ & $5.3[2-30]$ & 0.058 \\
\hline Duration of stay & $13.1[5-42]$ & $17.4[6-151]$ & 0.001 \\
\hline Pneumonia & 1 & 2 & \\
\hline Air leakage & 14 & 8 & \\
\hline Respiratory failure & 0 & 2 & \\
\hline Chylothorax & 2 & 3 & \\
\hline Cardiovascular & 3 & 3 & \\
\hline Bleeding & 0 & 2 & \\
\hline Others & 0 & 2 & \\
\hline Mortality & 0 & 1 & 0.26 \\
\hline Harvested lymph node number & $9.5[0-40]$ & $14[0-52]$ & $<0.001$ \\
\hline Upstaging & 2 & 2 & 0.82 \\
\hline
\end{tabular}

VATS, video-assisted thoracoscopic surgery.

two groups except longer operation time in VATS group (Table 4).

Oncological long-term outcomes were analyzed by Kaplan-Meier curve and log-rank test in Figure 1 (crude) and Figure 2 (propensity matched). Median follow-up period was 73.5 months. Disease-free survival in VATS was significantly better than open (5- and 10-year survival; VATS, $91.4 \%, 79.0 \%$; open, $85.1 \%, 73.6 \%$; respectively, $\mathrm{P}=0.04)$. Overall survival in VATS was not different from thoracotomy (5- and 10-year survival; VATS, $92.1 \%, 85.7 \%$; open, $89.6 \%$, $83 \%$; respectively, $\mathrm{P}=0.58$ ). However, the significantly better disease-free survival in VATS group were dissolved (5- and 10-year survival; VATS, 90.7\%, 72.6\%; open, $86.1 \%$, 73.5\%; respectively, $\mathrm{P}=0.17)$. Cox regression models for multivariate analysis showed that higher age, and T2 were significantly worse prognostic factors for overall survival (Table 5). However, after propensity matching, higher age in overall survival $[\mathrm{P}=0.04,95 \%$ confidence interval $(\mathrm{CI}):(1.02-6.81)]$ and $\mathrm{T} 2$ in disease-free survival [P=0.01, 95\% CI: $(1.41-17.3)]$ were significantly worse prognostic factors (Table 6).

\section{Discussion}

Thoracoscopic or VATS major pulmonary resection for early-stage NSCLC is feasible and safe (14), and shortterm oncological outcomes were comparable with open surgery (15). However, long-term outcomes more than 5 years remains unclear. Most of literatures of short-term results were non-randomized retrospective study and single institutional results. Despite of lack of well-established evidence, VATS may be applied for clinical practice of lung cancer surgery. There is no definition of long-term survival, but we simply defined long-term as follow up period longer than 5 years in this study. The growing results support VATS as one of the operative options to cure early-stage NSCLC; however, the lack of long-term outcomes of this approach may lead to be deterred by open preferred surgeons. In this study, we analyzed the perioperative and long-term oncological outcomes of thoracoscopic surgery in patients with clinical N0 lung adenocarcinoma. Since most of previous literatures reported oncological outcomes about NSCLC including non-adenocarcinoma, we focused 
Table 3 Characteristics of the patients (propensity matched)

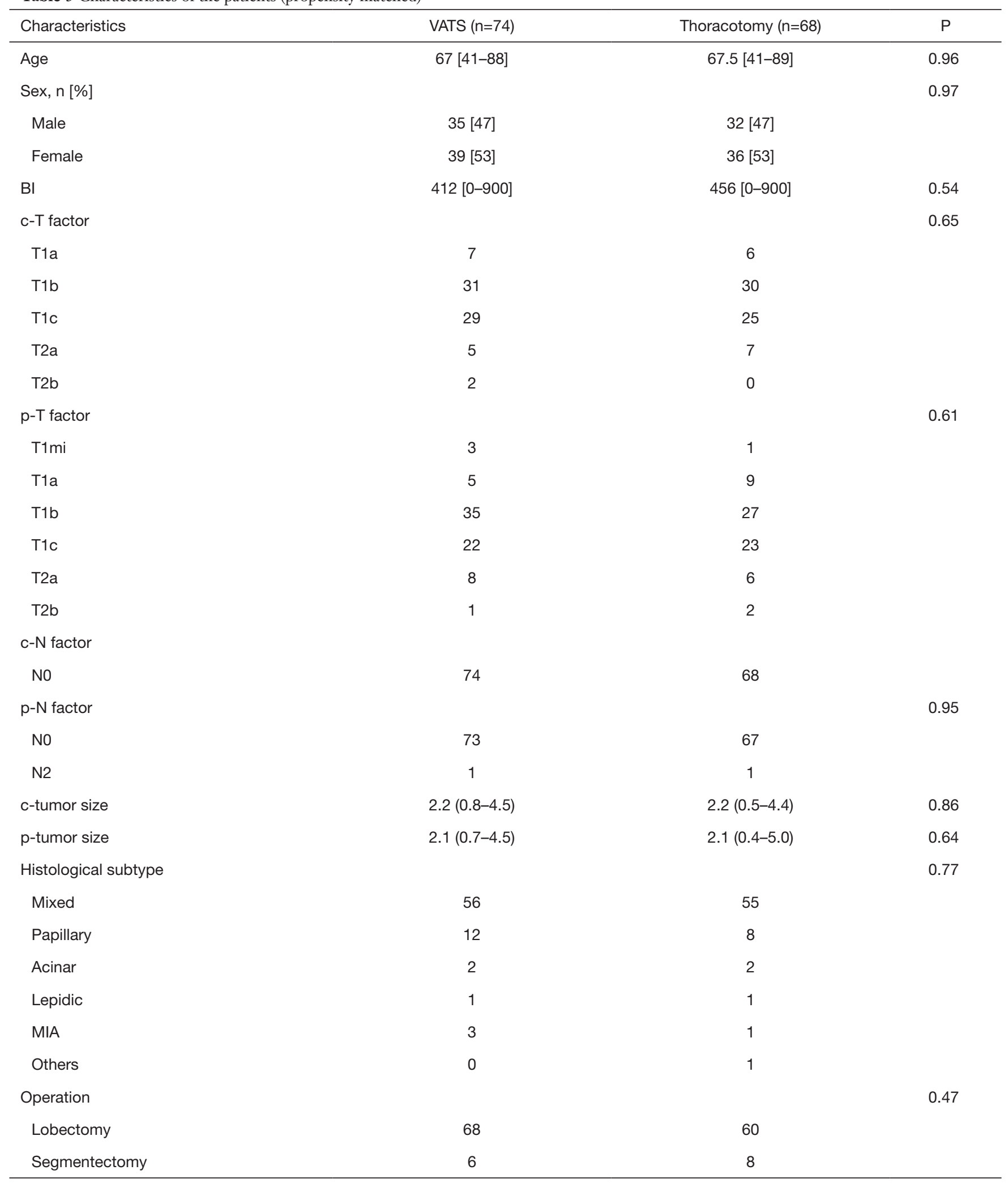

VATS, video-assisted thoracoscopic surgery; BI, Brinkman index; MIA, minimally invasive adenocarcinoma. 
Table 4 Perioperative outcomes (propensity matched)

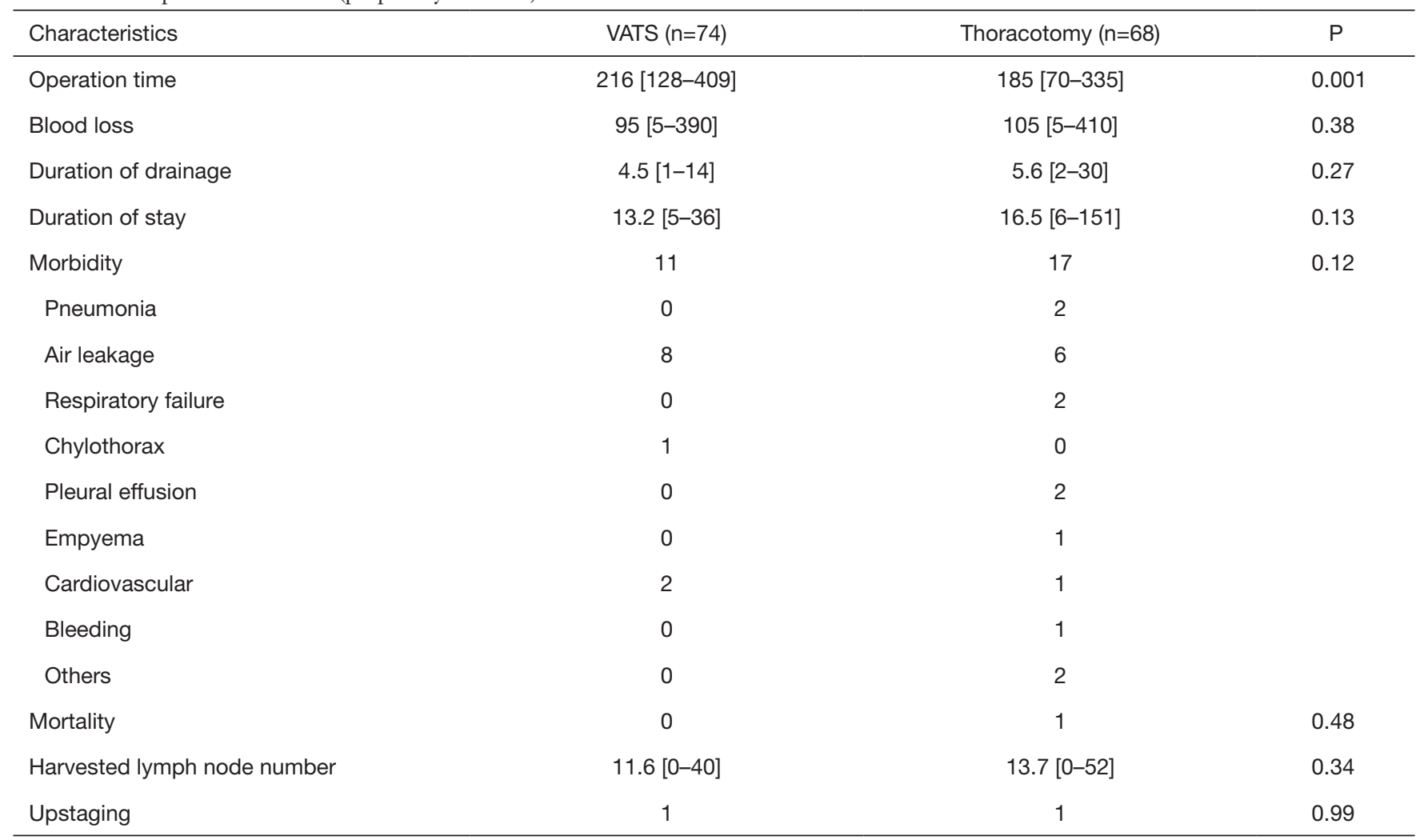

VATS, video-assisted thoracoscopic surgery.
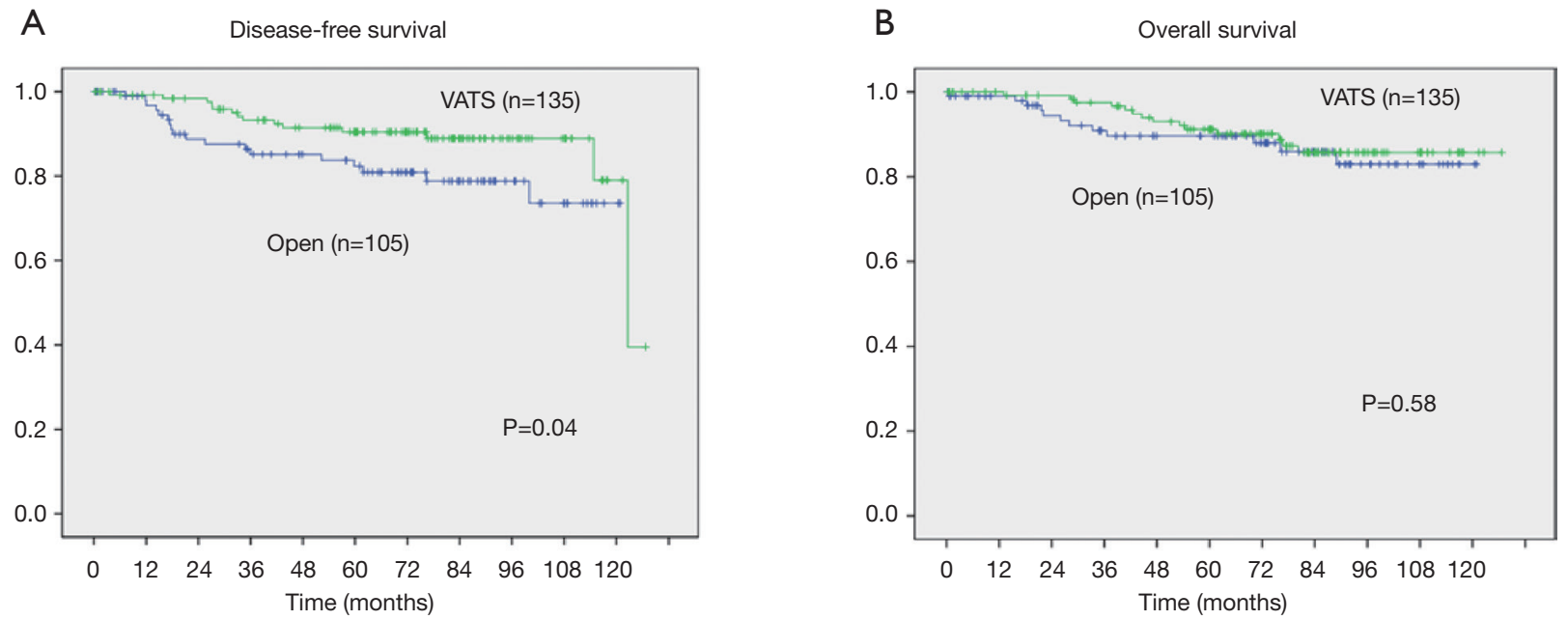

Figure 1 Disease-free survival (A) and overall survival (B) according to the approach. Statistical analyses were performed by the log-rank test. Five- and ten-year disease-free survival showed significant differences: $91.4 \%$ and $79.0 \%$ with VATS and $85.1 \%$ and $73.6 \%$ with open surgery, respectively $(\mathrm{P}=0.04, \mathrm{~A})$. Five- and ten-year overall survival did not show significant differences: $92.1 \%$ and $85.7 \%$ with VATS and $89.6 \%$ and $83 \%$ with open surgery, respectively $(\mathrm{P}=0.58, \mathrm{~B})$. VATS, video-assisted thoracoscopic surgery. 
A

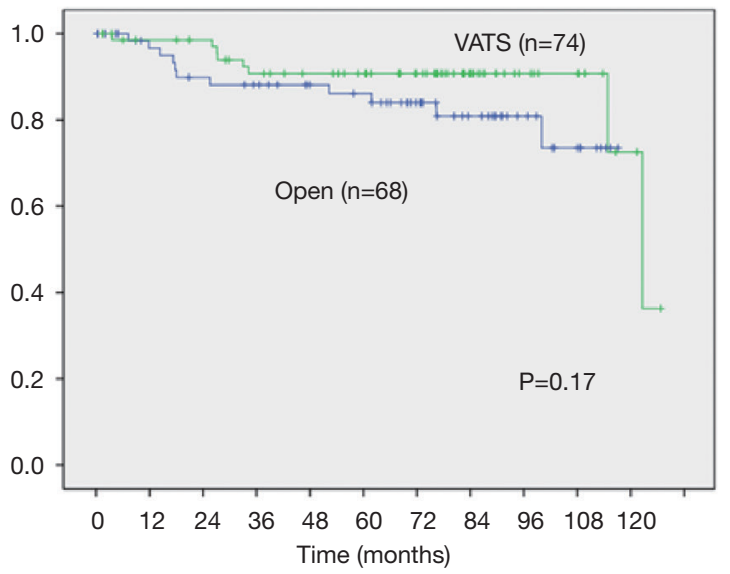

B

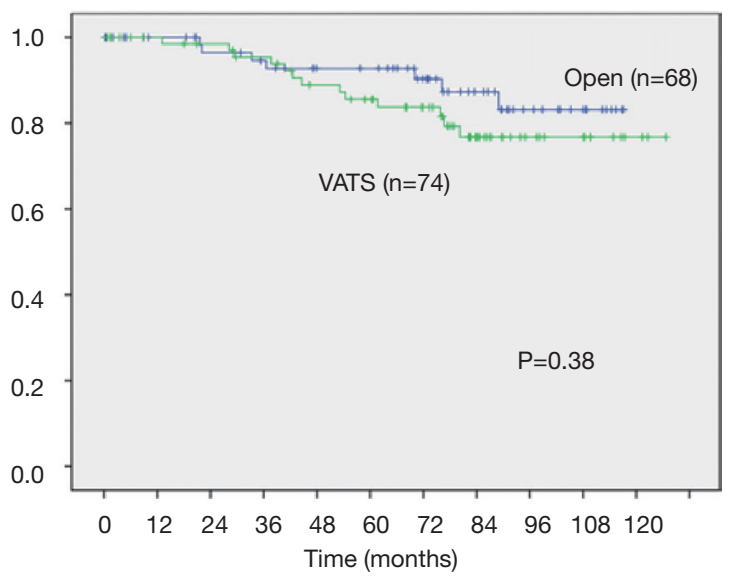

Figure 2 Disease-free survival (A) and overall survival (B) according to the approach after propensity matching. Five- and ten-year disease-free survival did not show significant differences: $90.7 \%$ and $72.6 \%$ with VATS and $86.1 \%$ and $73.5 \%$ with open surgery, respectively $(\mathrm{P}=0.17, \mathrm{~A})$. Five- and ten-year overall survival did not show significant differences: $87.2 \%$ and $76.8 \%$ with VATS and $92.8 \%$ and $83.1 \%$ with open surgery, respectively $(\mathrm{P}=0.38, \mathrm{~B})$. VATS, video-assisted thoracoscopic surgery.

Table 5 Disease-free and overall survivals according to Cox regression analysis (all cases)

\begin{tabular}{|c|c|c|c|c|c|c|}
\hline Variables & \multicolumn{3}{|c|}{ Overall survival } & \multicolumn{3}{|c|}{ Disease-free survival } \\
\hline Age (ref. <65) & 4.24 & $1.71-10.5$ & 0.002 & 1.43 & $0.65-3.14$ & 0.37 \\
\hline Gender (ref. male) & 0.56 & $0.18-1.72$ & 0.32 & 0.61 & $0.24-1.55$ & 0.29 \\
\hline $\mathrm{BI}($ ref. $<400)$ & 1.89 & $0.65-5.47$ & 0.24 & 1.28 & $0.52-3.17$ & 0.59 \\
\hline Subtype (ref. mixed) & 2.2 & $0.87-5.62$ & 0.09 & 1.25 & $0.49-3.22$ & 0.64 \\
\hline Approach (ref. thoracotomy) & 1.52 & $0.64-3.61$ & 0.34 & 0.54 & $0.24-1.25$ & 0.15 \\
\hline
\end{tabular}

$\mathrm{HR}$, hazard ratio; $\mathrm{Cl}$, confidence interval; $\mathrm{BI}$, Brinkman index.

Table 6 Disease-free and overall survivals according to Cox regression analysis (propensity matched cases)

\begin{tabular}{|c|c|c|c|c|c|c|}
\hline Variables & \multicolumn{3}{|c|}{ Overall survival } & \multicolumn{3}{|c|}{ Disease-free survival } \\
\hline Age (ref. <65) & 2.63 & $1.02-6.81$ & 0.04 & 0.98 & $0.36-2.67$ & 0.97 \\
\hline Gender (ref. male) & 0.47 & $0.14-1.57$ & 0.22 & 0.31 & $0.08-1.27$ & 0.11 \\
\hline $\mathrm{BI}($ ref. $<400)$ & 1.57 & $0.51-4.88$ & 0.43 & 1.38 & $0.4-4.78$ & 0.61 \\
\hline Subtype (ref. mixed) & 1.28 & $0.41-4.1$ & 0.67 & 1.39 & $0.43-4.54$ & 0.58 \\
\hline Approach (ref. thoracotomy) & 1.59 & $0.62-4.1$ & 0.33 & 0.4 & $0.14-1.13$ & 0.08 \\
\hline
\end{tabular}

$\mathrm{HR}$, hazard ratio; $\mathrm{Cl}$, confidence interval; BI, Brinkman index. 
on adenocarcinoma except non-adenocarcinoma because of pathological heterogeneity.

We evaluated the perioperative outcomes, including operating time, blood loss, duration of chest tube drainage, length of hospital stay, morbidity, mortality, dissected lymph node number and upstaging between two groups. Benefit of VATS was less blood loss and shorter stay but harm was longer operation time and less number of harvested lymph nodes compared with open surgery. These differences were similar as previous reports $(15,16)$. No different nodal upstaging which was different from other papers (5-7) may be due to small number of sample size or meticulous preoperative estimation of staging by CT or PET-CT.

The rates of postoperative morbidity was not statistically significant between VATS and open surgery. These results are comparable to previous reports, in which the mean morbidity rates were $5.1 \%$ to $58 \%$ in VATS lobectomy and $6 \%$ to $34 \%$ in open lobectomy $(17-19)$. The most frequent complication was prolonged air leakage longer than 7 days in both groups; however, VATS did not increase the rates of air leakage. Furthermore, as our results showed no operative mortality, in VATS, but only one case in open surgery due to acute respiratory failure. As analyzed after propensity matching, only operation time in VATS was longer than in open surgery. Advantage of VATS in terms of less blood loss and shorter hospital stay was eliminated. Furthermore, the disadvantage about less number of harvested lymph nodes in VATS was improved, which may lead to oncological outcomes. Morbidity and mortality was not different between two groups after propensity matching. Taken together, the safety of all VATS techniques in our series was confirmed.

In the oncological outcomes, we compared the results of recurrence rates or survival between VATS and open surgery. Significant differences between two groups were not found in disease-free and overall survivals. On the basis of lack of evidence for long-term survival, our 5-year survivals in both groups were better than ones previously reported $(16,20)$. Many Tis or T1 tumor may lead better prognosis in our study. After propensity matching, no differences of long-term disease-free and overall survivals were confirmed and these results may suggest that VATS has oncologically similar potential with open surgery because of well-balanced age, gender, $\mathrm{T}$ factor, tumor size, and histological subtype. Cox regression model showed that age, $\mathrm{T}$ factor and histological subtype was worse prognostic factor in overall survival, however, only age in overall survival and $\mathrm{T}$ factor in disease-free survival has a predictive value for worse prognosis after propensity matching. Although most of histological subtype was mixed subtype which was consisted with acinar and papillary component, we could not find any prognostic value compared with nonmixed subtype. Since AIS/MIA is known as preinvasive and minimally invasive lesion with better prognostic potential, small number of these subtype or lepidic subtype may not make a difference between mixed and non-mixed subtype (12).

Many factors influencing the outcome of survival and local recurrence with VATS have been proposed, such as lymph node dissection or sampling (21). Furthermore, longer follow up period are reflected by many confounding factor such as patients' physiological condition, but we focused simply survival and recurrence. Our standard operation for lung cancer was performed with systemic lymphadenectomy after lung resection using both procedures. The reason why the mean numbers of dissected lymph nodes in VATS group were significantly lower than in open group may be due to tumor size. Because lager tumor size in open group may lead to more number of lymph node dissection under curative intent. Otherwise, it may be a possibility that more number of ground glass nodule with partially solid component, former Noguchi's type B (data not shown) in VATS group may lead to less nodal dissection. After propensity matched analysis, this difference was rectified with well-balanced tumor size. On the other hand, nodal upstaging was similar between two groups in crude cases regardless of less number of dissected nodes. Although less upstaging by VATS remains still controversial, Yang et al. reported no different upstaging between VATS and open surgery under condition of similar tumor size (20). These studies may support our result.

The limitations of this study are retrospective analysis and is a single institutional study. Small number of patients in this retrospective study may lead to less significance to discover a disparity of oncological outcomes. Therefore, a definitive evidence by randomized controlled studies should be proposed among treatment groups, however, it may be difficult in real world because of many VATS surgery in clinical practice. On the basis of this limitation, propensity score analyses which may control a number of possible confounders were applied to this study and we observed no differences between two groups in survival outcome. However, propensity score methods can not adjust the unmeasured confounders such as physiological reserve.

In conclusion, our study demonstrated that longterm outcome in thoracoscopic surgery for early- 
stage adenocarcinoma was not inferior to open surgery in oncological issue. VATS resection in early-stage adenocarcinoma may be a treatment of choice for promising not only short-term outcomes but also long-term prognosis.

\section{Acknowledgments}

Funding: None.

\section{Footnote}

Reporting Checklist: The authors have completed the STROBE reporting checklist. Available at http://dx.doi. org/10.21037/jtd-20-2259

Data Sharing Statement: Available at http://dx.doi. org/10.21037/jtd-20-2259

Conflicts of Interest: All authors have completed the ICMJE uniform disclosure form (available at http://dx.doi. org/10.21037/jtd-20-2259). The authors have no conflicts of interest to declare.

Ethical Statement: The authors are accountable for all aspects of the work in ensuring that questions related to the accuracy or integrity of any part of the work are appropriately investigated and resolved. The study was conducted in accordance with the Declaration of Helsinki (as revised in 2013). Our institutional ethical committee approved the retrospective study and waived the need for patient consent (No. 12-2-10).

Open Access Statement: This is an Open Access article distributed in accordance with the Creative Commons Attribution-NonCommercial-NoDerivs 4.0 International License (CC BY-NC-ND 4.0), which permits the noncommercial replication and distribution of the article with the strict proviso that no changes or edits are made and the original work is properly cited (including links to both the formal publication through the relevant DOI and the license). See: https://creativecommons.org/licenses/by-nc-nd/4.0/.

\section{References}

1. Yan TD, Cao C, D'Amico TA, et al. Video-assisted thoracoscopic surgery lobectomy at 20 years: a consensus statement. Eur J Cardiothorac Surg 2014;45:633-9.

2. Scott WJ, Matteotti RS, Egleston BL, et al. A comparison of perioperative outcomes of video-assisted thoracic surgical (VATS) lobectomy with open thoracotomy and lobectomy: results of an analysis using propensity score based weighting. Ann Surg Innov Res 2010;4:1.

3. Denlinger CE, Fernandez F, Meyers BF, et al. Lymph node evaluation in video-assisted thoracoscopic lobectomy versus lobectomy by thoracotomy. Ann Thorac Surg 2010;89:1730-5; discussion 1736.

4. Imakiire T, Iwasaki A, Hamatake D, et al. Long-term patient outcome 10 years after video-assisted thoracoscopic surgery lobectomy for non-small-cell lung cancer. Asian J Endo Surg 2010;3:162-8.

5. Licht PB, Jørgensen OD, Ladegaard L, et al. A national study of nodal upstaging after thoracoscopic versus open lobectomy for clinical stage I lung cancer. Ann Thorac Surg 2013;96:943-9; discussion 949-50.

6. Boffa DJ, Kosinski AS, Paul S, et al. Lymph node evaluation by open or video-assisted approaches in 11,500 anatomic lung cancer resections. Ann Thorac Surg 2012;94:347-53; discussion 353.

7. Medbery RL, Gillespie TW, Liu Y, et al. Nodal Upstaging Is More Common with Thoracotomy than with VATS During Lobectomy for Early-Stage Lung Cancer: An Analysis from the National Cancer Data Base. J Thorac Oncol 2016;11:222-33.

8. D'Amico TA, Niland J, Mamet R, et al. Efficacy of mediastinal lymph node dissection during lobectomy for lung cancer by thoracoscopy and thoracotomy. Ann Thorac Surg 2011;92:226-31; discussion 231-2.

9. Su S, Scott WJ, Allen MS, et al. Patterns of survival and recurrence after surgical treatment of early stage non-small cell lung carcinoma in the ACOSOG Z0030 (ALLIANCE) trial. J Thorac Cardiovasc Surg 2014;147:747-52; discussion 752-3.

10. Li WW, Lee TW, Lam SS, et al. Quality of life following lung cancer resection: video-assisted thoracic surgery vs thoracotomy. Chest 2002;122:584-9.

11. Goldstraw P, Chansky K, Crowley J, et al. The IASLC Lung Cancer Staging Project: Proposals for Revision of the TNM Stage Groupings in the Forthcoming (Eighth) Edition of the TNM Classification for Lung Cancer. J Thorac Oncol 2016;11:39-51.

12. Travis WD, Brambilla E, Noguchi M, et al. International association for the study of lung cancer/american thoracic society/european respiratory society international multidisciplinary classification of lung adenocarcinoma. J Thorac Oncol 2011;6:244-85.

13. Yamashita S, Chujo M, Kawano Y, et al. Clinical impact of 
segmentectomy compared with lobectomy under complete video-assisted thoracic surgery in the treatment of stage I non-small cell lung cancer. J Surg Res 2011;166:46-51.

14. Hwang Y, Kang CH, Kim HS, et al. Comparison of thoracoscopic segmentectomy and thoracoscopic lobectomy on the patients with non-small cell lung cancer: a propensity score matching study. Eur J Cardiothorac Surg 2015;48:273-8.

15. Nwogu CE, D'Cunha J, Pang H, et al. VATS lobectomy has better perioperative outcomes than open lobectomy: CALGB 31001, an ancillary analysis of CALGB 140202 (Alliance). Ann Thorac Surg 2015;99:399-405.

16. Stephens N, Rice D, Correa A, et al. Thoracoscopic lobectomy is associated with improved short-term and equivalent oncological outcomes compared with open lobectomy for clinical Stage I non-small-cell lung cancer: a propensity-matched analysis of 963 cases. Eur J Cardiothorac Surg 2014;46:607-13.

17. McKenna RJ Jr, Houck W, Fuller CB. Video-assisted thoracic surgery lobectomy: experience with 1,100 cases. Ann Thorac Surg 2006;81:421-5; discussion 425-6.

Cite this article as: Yamashita SI, Tokuishi K, Moroga T, Nagata A, Imamura N, Miyahara S, Yoshida Y, Waseda R, Sato T, Shiraishi T, Nabeshima K, Kawahara K, Iwasaki A. Long-term survival of thoracoscopic surgery compared with open surgery for clinical N0 adenocarcinoma. J Thorac Dis 2020;12(11):6523-6532. doi: 10.21037/jtd-20-2259
18. Villamizar NR, Darrabie MD, Burfeind WR, et al. Thoracoscopic lobectomy is associated with lower morbidity compared with thoracotomy. J Thorac Cardiovasc Surg 2009;138:419-25.

19. Whitson BA, Groth SS, Duval SJ, et al. Surgery for earlystage non-small cell lung cancer: a systematic review of the video-assisted thoracoscopic surgery versus thoracotomy approaches to lobectomy. Ann Thorac Surg 2008;86:200816; discussion 2016-8.

20. Yang CJ, Kumar A, Klapper JA, et al. A national analysis of long-term survival following thoracoscopic versus open lobectomy for stage I non-small-cell lung cancer. Ann Surg 2019;269:163-71.

21. Darling GE, Allen MS, Decker PA, et al. Randomized trial of mediastinal lymph node sampling versus complete lymphadenectomy during pulmonary resection in the patient with $\mathrm{N} 0$ or N1 (less than hilar) non-small cell carcinoma: results of the American College of Surgery Oncology Group Z0030 Trial. J Thorac Cardiovasc Surg 2011;141:662-70. 